\title{
ENTREVISTA A ELLEN LEWIN
}

www.aibr.org

\section{Entrevista: José Ignacio Pichardo Galán}

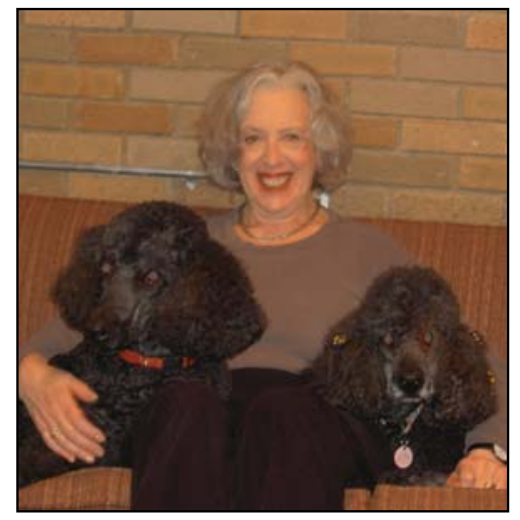

Ellen Lewin es profesora de estudios de la mujer y de antropología social en la Universidad de lowa (Estados Unidos). Comenzó su carrera como antropóloga con una investigación sobre madres lesbianas, cuyo trabajo de campo se alargó durante casi 10 años desde finales de los 70 hasta los años 80. Su libro Lesbian Mothers: Accounts of Gender in American Culture fue publicado en inglés en 1993 y es desde entonces un referencia obligada en el estudio del parentesco homosexual.

Posteriormente ha trabajado sobre ceremonias y rituales de compromiso entre parejas homosexuales y actualmente ultima un libro sobre padres gays. Entre sus intereses teóricos están el feminismo, la teoría de género y la maternidad.

Usted es una de las antropólogas pioneras en estudios sobre lesbianas, gays, bisexuales y transexuales (LGBT) en los años 70. ¿Qué diferencia ve entre la actitud de la antropología social hacia los estudios de LGBT hace 30 años y la de hoy en día?

Ellen Lewin (EL): Coedité un libro, Out in Theory, sobre la influencia de los estudios de gays y lesbianas en la antropología y viceversa y comprobé que lo que llamamos "antropología gay y lésbica" se ha convertido realmente en un campo de estudio. Y una forma de comprobar que es así es porque ha habido un par de grandes artículos de revisión al respecto en el Anual Review of Anthropology, lo que le da una especie de "estatus oficial". Uno fue a mediados de los 90: "Gays y lesbianas en la casa de la antropología" de Kath Weston, y hay otro nuevo que va a salir muy pronto. Ahora que tenemos dos artículos de revisión, iparece que existimos! La otra prueba de que nos estamos consolidando como campo de estudio es que la gente joven está consiguiendo trabajos. Yo estuve durante 22 años sin un trabajo "de verdad" por el tipo de investigaciones que hacía. La mayor parte de la gente de mi generación consiguió puestos de trabajo por investigar en otras áreas y después se pusieron a hacer estudios de gays y lesbianas. Ahora es distinto, la gente joven que hace trabajo de campo con gays y lesbianas puede presentarlo. Es simplemente algo aceptado, quizás controvertido, pero está bien. Otra muestra es que nuestros textos se publican fácilmente. Antes había que publicar en editoriales marginales y ahora los libros están saliendo de las principales editoriales, de universidades 
prestigiosas... Y esto también ocurre en parte porque la gente compra estos libros, se venden bien. Además tenemos una organización, la Society of Lesbian and Gay Anthropologists, y hemos sido capaces de tutorizar gente joven que quizás en sus instituciones no tienen profesores con los que puedan trabajar. Hemos apoyado a un montón de gente haciendo posible que puedan trabajar en estos temas. Hay gente como Martin Manalansan, que trabaja sobre drag queens filipinas o David Valentine que trabaja sobre transexuales, son grandes investigadores, están haciendo muy buenos estudios y están obteniendo reconocimiento. Y yo acabo de ser elegida para la junta directiva de la American Anthropological Association ¡Es algo grande! ¡La gente votó por mí! Y no fue sólo la gente gay. Pienso que estamos ganándonos mucho respeto.

\section{¿Es difícil conseguir financiación para este tipo de investigaciones?}

EL: Conseguir fondos del Gobierno Federal es muy difícil. No obstante, uno de mis estudiantes está haciendo un estudio increíble sobre el uso de la testosterona que incluye a transexuales que quieren pasar de mujer a hombre; él lo llama "la medicalización de la masculinidad" y ha conseguido fondos de la National Science Foundation y de una fundación privada. Yo misma tuve que disfrazar mi investigación sobre madres lesbianas presentándola como una investigación sobre madres solteras, pero no sólo ante la institución que me financiaba, sino también ante mi misma. Esto era en el año 1977 y no podía decirme a mi misma directamente que eso era lo que estaba haciendo, aunque en el fondo sabía que era eso lo que estaba haciendo, pero no me sentía totalmente bien. Y cuando se lo comentaba a la gente me decían “¿Qué? ¿Qué es eso? ¡No existen las madres lesbianas: las lesbianas no pueden tener relaciones sexuales!" Simplemente no lo entendían. Entonces me planteé que el estudio podía tratar sobre "madres solteras" y entrevisté también a mujeres heterosexuales. Por eso tardé tanto tiempo escribir el libro, porque tenía un esquema que no tenía sentido. Me atasqué y no podía seguir. Lo dejé de lado durante un tiempo, me deprimí y no podía trabajar en el tema. Y cuando volví a ello lo estructuré de forma totalmente diferente: era sobre madres lesbianas. Yo también tenía que madurar y tener más confianza en mí misma ya que nada de esto fácil: salir del armario es duro y esto era una especie de salida del 
armario profesional. Tenía que admitir yo misma que eso era realmente lo que estaba haciendo.

¿Usted opina que debe mantenerse una separación entre los estudios LGBT y los "estudios de la mujer" (Women Studies), o que por el contrario son campos muy relacionados y que deberían desarrollarse de manera más conjunta?

EL: A veces van juntos. Los "estudios de la mujer" cada vez están cambiando más su nombre a "estudios de género". En nuestro departamento de momento no lo hemos hecho, principalmente por razones sentimentales y porque mucha gente piensa que si no lo llamamos "estudios de la mujer" muchas mujeres se verán apartadas y la historia de los estudios feministas se verá borrada. Yo antes pensaba igual, pero ahora pienso cada vez más que nos debemos llamar "estudios de género". En nuestra universidad tenemos un programa de "estudios de la mujer" y un programa muy pequeño de "estudios sobre sexualidad" y no tiene ningún sentido que estemos separados. Yo formo parte de un grupo que quiere que trabajemos juntos pero hay bastantes resistencias al respecto porque piensan que son dos áreas o campos diferentes, aunque no lo son. Pero, para serte franca, hay gente en "estudios de la mujer" que no quiere trabajar con hombres. Desafortunadamente todavía existen este tipo de problemas aunque pienso que al final los dos campos acabarán yendo juntos.

¿Qué opina de los estudios queer que se basan en el campo de la crítica literaria o en los "estudios culturales"?

EL: Pienso que muchos de los estudios queer o estudios de género son muy literarios, que efectivamente están más basados en la literatura o estudios culturales que en la antropología, y ese no es el tipo de trabajo que quiero hacer. Estos estudios, aunque sean interesantes, los veo poco empíricos. Sin embargo, a mi me hace falta la antropología. Todo el mundo está hablando sobre estas "producciones culturales", como si supieran lo que significan. Y yo les preguntaría "¿Cómo sabes qué significa eso? ¿Has preguntado a alguien? Los "fundamentalistas queer" dicen: "iTenemos que ser diferentes, tenemos que resistir!". Eso es muy bonito, pero la gente real no se siente así. Muchos de ellos quieren tener sus familias, quieren pasar las Navidades con sus padres... Eso es lo que quieren y tenemos que 
reconocer que esta gente existe y son de verdad. $Y$ que quizás sus deseos y expectativas no son revolucionarias, pero son reales. Los antropólogos estudiamos personas reales. Por eso tengo problemas con este tipo de estudios culturales idealizados, y echo en falta la perspectiva antropológica en este campo.

\section{Usted estudió la maternidad lésbica, ¿Cómo llegó a interesarse por la paternidad de los hombres gays?}

EL: Entre ambos estudios, realicé una investigación sobre ceremonias de compromiso. Leí las memorias de un padre gay, The Velvetine Father, en una sola noche sin poder siquiera ir a dormir y por la mañana me dije a mí misma: este es mi próximo proyecto. Porque él hablaba sobre su apasionamiento por ser padre y aquí entramos en la teoría de género, que está basada en buena medida en la noción de que existen dos géneros a causa de la maternidad, y hay diferentes explicaciones al respecto: es biológico, es cultural, es esto o lo otro... pero aparentemente los hombres no desean realmente y con urgencia tener hijos. Por supuesto que sí lo desean, pero culturalmente es algo invisibilizado. Así que empecé a pensar en cómo la historia de este hombre es diferente a la de las lesbianas, porque las madres lesbianas pueden quedarse embarazadas como sea y como mujeres se ven con el derecho a hacerlo. Pero para los hombres es muy difícil porque en primer lugar no pueden quedarse embarazados y por otro lado nadie espera de ellos que quieran tener hijos. Por eso tienen que idear una forma de encontrarle sentido a todo esto, así como una forma de superar estos obstáculos, lo que les exige una dedicación extraordinaria. Yo sentía muchísima curiosidad sobre qué pensaban los hombres gays de todo esto. Pensé que quizás se veían a sí mismos como madres. Hay un libro muy famoso de la antropología del Caribe titulado My Mother Who Fathered Me (Mi madre que me crió como un padre), sobre familias matrifocales, así que pensé que quizás esto iba a ser como "My Father Who Mothered Me" (Mi padre que me crió como una madre). Pero no funcionaba así, cuando empecé a hablar con estos hombres en la mayoría de los casos decían que ellos no eran madres, simplemente porque no son mujeres. Pero, de hecho, su comportamiento es de madres. Esto hace que verdaderamente te vuelvas a cuestionar ¿dónde está el género? De forma teórica no lo sé. 
Muchos de los temas que estoy tratando en este libro son similares a lo que hice en los dos libros anteriores. Estoy mirando a las narrativas en términos de temas. Tengo un capítulo sobre los discursos morales, otro sobre los padres diciendo que ya no son gays, otro sobre cómo imaginan la familia... Dicen: "quiero tener una familia y para tener una familia tienes que tener niños porque si no, no es una familia". Otro capítulo recoge todas las cuestiones de la naturalización: como si la paternidad fuera algo que les viniera de dentro, algo que está ahí pero no saben por qué, algunos lo llaman Dios... Y el último capítulo, que no he comenzado aún, trata sobre el consumo. Porque mucho de lo que ocurre aquí es muy comercial. Estos bebés son evaluados por lo que cuestan y a veces pueden convertirse en posesiones. Para los hombres que optan por la maternidad subrogada (vientres de alquiler), supone un gasto de muchísimo dinero y toman sus decisiones imaginando el tipo de hijo que quieren; cuáles quieren que sean sus rasgos; a quién quieren que se parezca... quieren estar biológicamente conectados con el bebé.

Esto ocurre con todo el mundo, también con los heterosexuales que van a tener hijos: imaginan de alguna manera cómo será su bebé y hasta cierto punto, el bebé se convierte en un objeto de consumo. Hay un artículo realizado por una demógrafa, Judith Blake, que habla de "niños consumibles". Ya no somos granjeros, así que los niños no van a ir a cosechar el maíz ni nada parecido: son caros, cuestan más de lo que dan, ¿qué es lo que obtenemos de ellos? ¿Por qué los tenemos? Hasta cierto punto es consumo de prestigio. En los Estados Unidos y en otros países capitalistas, llevamos Levi's, o tenemos un tipo de coche... Veo que algo de eso está pasando, pero es muy sutil y estoy muy preocupada en cómo escribir sobre esto porque no quiero desacreditar a esta gente. Porque ellos aman a sus hijos y son padres encantadores, pero al mismo tiempo están maximizando diversas imágenes, así que este es el capítulo que más miedo me da. Voy a trabajar en él pronto, pero tengo que encontrar una forma de hablar de ello de forma que no cree algo que pueda sea utilizado contra ellos.

\section{¿Cómo están afectando las demandas de gays y lesbianas en términos de familia y parentesco a las teorías del parentesco?}

EL: Las teorías del parentesco están viéndose muy influidas hoy por la reproducción asistida. Todo el mundo, como por ejemplo Marilyn Strathern, está hablando de 
cómo estas imágenes de la familia están cambiando en respuesta a las nuevas tecnologías. Y todo esto forma parte de esa discusión. Esa es otra de las formas en las que estamos siendo integrados en la corriente principal de la antropología, ya que a menudo se nos incluye en las discusiones sobre parentesco. Y la gente está hablando también sobre reproducción asistida o sobre las varias formas de tecnologías sociales que cambian los significados del parentesco. Hay trabajos muy interesantes sobre el tema: cómo la gente imagina, por ejemplo, de quién quieren obtener la donación del óvulo para su hijo. Si no tienen parientes van a decir: "yo quiero una donante que sea también negra, o también italiana". Lo imaginan como una forma de parentesco. Y las mujeres piensan en los donantes de esperma como en una especie de parientes, o que si sus hijos tienen el mismo donante de semen son parientes unos de otros. Maureen Sullivan en su libro The family of women, mucho más reciente que el mío, estudia parejas lesbianas en California que han tenido hijos a través de la reproducción asistida. Una de las cosas que ocurre a menudo en estas familias es que descubren que han tenido el mismo donante de semen, el donante es anónimo, ellas no saben quién es, pero conocen su número en la clínica y si coincide muchas deciden considerarse parientes.

\section{Usted hizo trabajo de campo en su propio contexto cultural y para muchos eso no es considerado un verdadero trabajo de campo. ¿Cómo ve este tema?}

EL: Eso ocurre todavía en Estados Unidos. Pero la realidad es que mucha gente no se puede ir al extranjero porque no consigue becas. Es muy difícil conseguir becas, no importa el campo en el que trabajes. Y luego hay muchas partes del mundo en las que sencillamente no quieren que vayas. Dicen “¿Qué eres? ¿Antropólogo? ¡No queremos hablar contigo! Tenemos nuestra propia antropología". Piensan que es una empresa colonialista, y a veces tienen razón. Entonces irse al extranjero para hacer trabajo de campo es cada vez más difícil. Además, la gente mira a su alrededor y ve que pasan cosas muy interesantes, así que cada vez hay más y más gente haciendo esto: en mi departamento, probablemente la mitad de los estudiantes trabajan en los EEUU y, sin embargo, nadie les enseña "Cultura estadounidense", simplemente se asume que ya saben sobre el tema. Pero es un campo de estudio, ellos no han estudiado este tema. Yo no estoy segura de saber mucho, pero al menos he leído sobre ello. Enseñaba de forma esporádica un curso 
sobre lo que los EEUU son antropológicamente hablando, pero nadie se matriculaba, así que dejé de ofertarlo.

Todavía tenemos ese problema. La gente minimiza el hecho de hacer trabajo de campo en EEUU, te dicen: "Ah, eres una insider". Yo pienso que una nunca es una "insider", desde el momento en que estás haciendo investigación dejas de ser una insider y te conviertes en una "halfy", eres la mitad de esto y la mitad de aquello, y nunca puedes ser realmente una insider. Por ejemplo, cuando estaba haciendo el trabajo sobre mujeres lesbianas pensé, "bueno, yo soy lesbiana", pero para las mujeres con las que estaba trabajando, yo no tenía nada que ver con ellas porque yo no era madre. Escribí un artículo sobre esto titulado "Writing lesbian ethnography". Hay gente que dice que si eres una insider tendrás una visión tendenciosa, pero no existen realmente los insider, especialmente cuando haces antropología. Cuando hago etnografía o entrevistas yo no interactúo de igual manera que en mi vida normal: no respondo a sus comentarios, toda mi conversación está dirigida a facilitar que la persona con la que hablo se exprese lo más posible. En cierta medida podría decirse que no es mi personalidad real, sino mi personalidad de trabajo de campo, a veces digo cosas estúpidas simplemente para obtener respuestas y no me importa que piensen que soy idiota o algo parecido. Es muy engañoso trabajar en tu propio contexto cultural porque piensas que sabes cosas que realmente no conoces.

\section{Háblenos de su actividad docente actual y de sus próximos proyectos de investigación.}

EL: Actualmente doy clases en el Departamento de Estudios de la Mujer de la Univesridad de lowa, pero también enseño Antropología, así que no sólo trabajo en estos temas. Mi trabajo se sitúa entre estos dos campos: antropología, cultural e incluso médica, y en los estudios interdisciplinares de la mujer, aunque mi trabajo no es tan interdisciplinar. Así que siento que incorporo a mi trabajo cosas que no son únicamente lésbicas o gays $\mathrm{y}$, al tiempo que mi carrera se va desarrollando, los temas de interés se vuelven cada vez más amplios. Cada vez hay más temas nuevos y miles de cosas que quiero leer y cada vez hay más y más. Estoy rodeada en casa de pilas de libros que quiero leer y que nunca leo. ¡Cuando vivía en California pensaba que si había un terremoto moriría enterrada por todos mis libros 
por leer! Siempre trato de aprender cosas nuevas porque cuando yo estudiaba leíamos a Bourdieu y Foucault... y ahora siento que estoy todo el tiempo intentando ponerme al día con las nuevas teorías, muchas de las cuales pienso que son aburridas, por cierto. Por eso a menudo vuelvo a Goffman y a todos ellos, que muchas veces son más útiles para mi trabajo. Odio este lenguaje posmodernista de moda, tan difícil de entender.

Mi trabajo esta ahora muy centrado en la maternidad y en las muchas cuestiones en torno a este asunto, aunque ahora no hago trabajo de campo sobre el tema. Enseño cursos sobre maternidad y reproducción y me encanta ser docente de estas materias ¡Es fascinante! Estoy fascinada por estos temas, por las ideologías de la maternidad... Mi próximo proyecto, tras estudiar la paternidad de hombres gays, es estudiar las iglesias donde acuden hombres gays negros, en las que fui muy bien acogida durante mi trabajo de campo en Chicago. Y me atrae porque no sé mucho sobre religiones y ahora tengo que aprender mucho sobre el asunto. Me encanta explorar algo totalmente nuevo. 